\title{
Identidad local y multiculturalismo en un municipio rural catalán. El caso de Vila-rodona
}

\author{
Carla Aguilar Cunill \\ Politóloga \\ Máster en Migraciones y Mediación Social \\ Universitat Rovira i Virgili \\ carla.aguilar.c@gmail.com
}

Resumen: Este articulo pretende presentar brevemente los resultados de una investigación más amplia llevada a cabo entre 2010 y 2012 en la que analizaba la situación social existente en el municipio de Vila-rodona, un pequeño municipio rural catalán en el que conviven unas quince nacionalidades diferentes, situación a la que se ha llegado en pocos años. La población extranjera despierta sentimientos muy diferenciados dependiendo de su lugar de origen, siendo la más numerosa la de origen marroqui, que a la vez es la que lleva más tiempo en el municipio y despierta un mayor rechazo por parte de los habitantes autóctonos. Por otro lado, analizaré cómo su presencia ha fortalecido mucho el sentimiento identitario y de grupo de los babitantes "de toda la vida" o autóctonos.

Palabras clave: inmigración, municipio rural, identidad, género, exclusión.

Abstract: This article aims to briefly present the results of a larger study conducted between 2010 and 2012 which analyzed the social situation in the municipality of Vila-rodona, a small rural town in Catalonia where in the space of a few years over fifteen different nationalities have come to be living together. Depending on their place of origin, the foreign population invokes very different feelings among the native inhabitants. Moroccans form the largest and longest-established foreign community in the town and also elicit the highest negative response from the natives. The study also analyzes how much the presence of foreigners has strengthened the sense of identity and group among native people.

Keywords: immigration, rural municipality, identity, gender, exclusion. 


\section{Introducción}

Este texto parte de una investigación más amplia que realicé como trabajo final de máster entre 2010 y 2012 llamada "Las relaciones interculturales en Vilarodona". En ella analizaba los procesos migratorios que ha experimentado un pequeño municipio rural tarraconense, Vila-rodona, y profundizaba en la situación actual de las relaciones entre los vila-rodonins de toda la vida, a los que llamo autóctonos, y los forasteros.

El estudio tiene dos puntos de interés. En primer lugar, el estar centrado en un contexto rural, ya que existen pocos trabajos que lo tengan en cuenta. Este trabajo contribuye a cuestionar la relación que se suele establecer entre multiculturalismo y sociedad urbana, demostrando la existencia también de mucha diversidad en los entornos rurales. Diversidad que no solo es fruto de la inmigración, sino también de la tendencia a una creciente urbanización del modo de vida de su población. El segundo punto de interés de esta investigación se encuentra en el caso concreto de Vila-rodona y su situación de gran complejidad y problematización de la diversidad.

He realizado la investigación a partir de un trabajo de campo basado en 15 entrevistas formales, hechas a una persona de cada nacionalidad, y en las entrevistas con mi informante principal y las entrevistas informales con los habitantes con los que podía tener contacto. También utilicé la observación participante, consistente en estar presente e intervenir en determinados espacios o actividades del pueblo. Asimismo, he tenido en cuenta datos de tipo cuantitativo, recopilados principalmente del padrón de habitantes.

En este artículo me centro en qué es lo que define a una parte de la población como autóctona y cómo esta parte de la población etiqueta y categoriza al resto de inmigrantes y bajo qué criterios. Dado que en la investigación los inmigrantes marroquíes aparecen como los más estigmatizados, me centraré más en esta parte de la población y en cómo son percibidos por los autóctonos. También haré un breve inciso en torno a la consecuencia última de esta categorización: las diferentes situaciones de exclusión en el municipio.

He estructurado el artículo en nueve apartados, más la introducción. En los dos primeros hago una introducción al municipio de Vila-rodona y a la inmigración en este municipio. El tercer apartado está dedicado a describir quiénes son los autóctonos en Vila-rodona y cómo es su identidad. El cuarto descri- 
be las diferentes categorías de inmigrantes que existen entre los autóctonos, y el quinto, el sexto y el séptimo están dedicados a la comunidad marroquí. El octavo trata de las situaciones de exclusión que he observado en el municipio, y el noveno y último expone las conclusiones del artículo.

\section{Vila-rodona}

Vila-rodona es un municipio de interior situado en la provincia de Tarragona. Tiene una población de 1.279 habitantes, lo que lo identifica como municipio rural, al menos estadísticamente, ya que tiene menos de 2.500 habitantes.

Históricamente ha sido un pueblo agrícola y, pese a que hoy en día hay más población ocupada en los sectores de la industria y el comercio, su población sigue identificándolo como tal. Los cultivos de Vila-rodona son básicamente viñas y en los últimos años se han mecanizado de manera importante, lo que ha reducido la cantidad de mano de obra necesaria en este sector. Según datos del Ayuntamiento, la crisis se ha notado sobre todo en el sector de la construcción, especialmente importante en la localidad hasta hace unos años, y en el de la agricultura, sector en el que la crisis se ha unido a la antes mencionada mecanización de los cultivos, lo que ha aumentado mucho el número de personas en paro, según datos de la Cooperativa Agrícola.

La industria está compuesta por dos fábricas situadas en el término municipal: Precat y Pirogestion. De las dos se critica que la mayoría de sus trabajadores son de municipios cercanos o inmigrantes de Vila-rodona. En este municipio el comercio es especialmente numeroso. Hay tres supermercados pequeños, uno de los cuales es de comida halal, un estanco, una farmacia, una mercería, una panadería y una oficina bancaria. Los vecinos están especialmente orgullosos de tener la farmacia y el banco, pues no siempre hay en los pueblos y conllevan que muchos habitantes de los pueblos vecinos se desplacen a Vilarodona. También hay algunos servicios públicos que tampoco se encuentran en muchos municipios rurales, como guarderías, CAP, escuela pública, local de jubilados público, dos campos de fútbol...

Vila-rodona es descrito por sus habitantes como un poble viu ("pueblo vivo") por tener actividad y no haber perdido población. Es un orgullo para sus habitantes más históricos resaltar el gran número de comercios y servicios públicos del pueblo y poder decir que hay 18 entidades y asociaciones muy 
diversas, todas ellas activas. Este carácter hace especial al municipio y provoca el orgullo de sus habitantes e incluso la llegada de nuevos vecinos.

A continuación recojo las asociaciones que considero más importantes para mi trabajo. En unos casos, debido a su gran capacidad aglutinadora y, en otros casos, por su intervención en las relaciones interculturales en el municipio: 1) Grup de voluntaris/es d'ensenyament català a estrangers: es un grupo compuesto principalmente por personas que pertenecen o han pertenecido al sector de la educación y que voluntariamente dan clases de idioma y cultura local a los recién llegados; 2) Colłlectiu de Dones: es una asociación de mujeres que organiza talleres, excursiones, charlas, comidas, etc.; las mujeres que la componen tienen alrededor de 50 o 60 años y están en contacto con la red de asociaciones de mujeres de la comarca, con las que a veces también realizan actividades conjuntamente; 3) Associació de Jubilats i Pensionistes de Vila-rodona: sus miembros, como su nombre indica, son jubilados y pensionistas del municipio; organizan actividades muy en la línea de la asociación anterior y las mujeres suelen participar en ambas, incluso el local es compartido por los dos colectivos; 4) Centre d'Estudis del Gaià: es una asociación que se dedica principalmente a recoger y difundir información sobre la historia y la cultura de Vila-rodona y de toda la zona del río Gaià.

Desde el punto de vista histórico, las entidades más importantes del municipio son la cooperativa agrícola y el Casal. La cooperativa agrícola es una entidad formada por socios en la que se realiza la transformación de los productos agrícolas, sobre todo vitivinícolas, producidos por y la comercialización posterior. Esta comercialización se realiza en su mayor parte mediante la venta a granel para las principales marcas del sector, pero también se hace bajo la etiqueta de "Castell d'Or", que es la marca propia del municipio, inscrita dentro de la DO Tarragona. El Casal también es una entidad de socios, en este caso enfocada al ocio local. Gestiona una piscina, un cine, un bar y una pista de tenis, en los que también organiza talleres y actividades para los socios como clases de natación, bailes o partidas de dominó.

\section{La inmigración en Vila-rodona}

Actualmente el $17 \%$ de la población de Vila-rodona es extranjera. Pero antes de analizar la situación actual de la inmigración, haré un repaso de los diferen- 
tes movimientos de población que ha experimentado Vila-rodona en su historia reciente, que debemos conocer para entender las actuales relaciones entre sus habitantes.

\section{Gráfico 1. Población de Vila-rodona según nacionalidad española o extranjera}

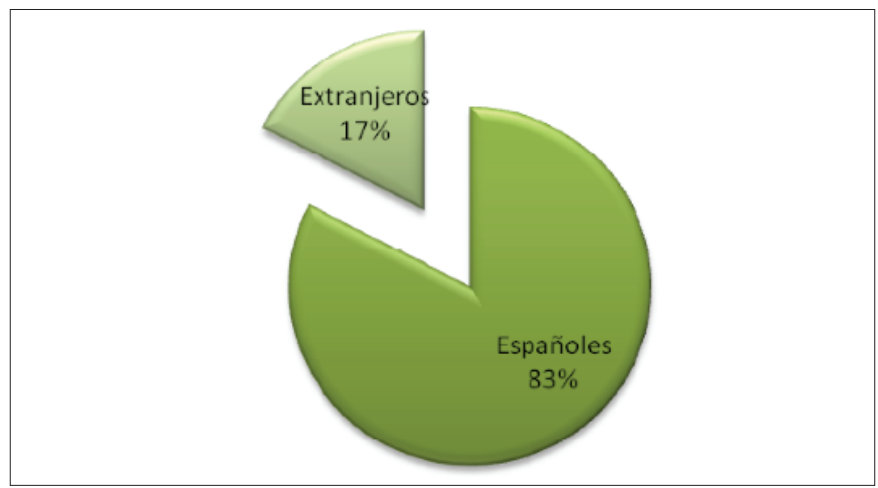

Fuente: Padrón de habitantes (Ayuntamiento de Vila-rodona) a fecha de 11/05/2011

En primer lugar, durante los años cincuenta llegaron a Cataluña, y también a Vila-rodona, muchos inmigrantes del sur del país. Los que llegaron al municipio provenían de Andalucía y Murcia. Su llegada causó una importante impresión entre los vecinos “autóctonos", que por primera vez conocían a personas que no entendían el catalán, y quizás por ello se les llamó els castellans ("los castellanos"). En primer lugar llegaron los hombres para trabajar en la agricultura $y$, una vez establecidos, trajeron a sus mujeres e hijos. Mis informantes iban a la escuela en aquella época y recuerdan perfectamente los primeros niños que entraron en ella:

Van arribar els castellans. Perquè jo era petita i mén recordo. Eh! Que han arribat els castellans! Que aquí no en teníem cap, tothom enraonava com naltros (Ramona, Associació de Dones).

La relación con los inmigrantes castellanos parece que fue fácil, aunque, según una informante castellana que aún vive en el pueblo, nunca han llegado a ser iguales. Los "autóctonos" nunca llegaron a considerarlos habitantes de pleno 
derecho, aunque a sus hijos sí, según algunos informantes, por haber sido escolarizados en el municipio y saber perfectamente el catalán.

El segundo movimiento de población ha sido la emigración, normalmente hacia zonas urbanas próximas. Esta emigración parece que estuvo compuesta también por muchos castellanos que, después de vivir unos años en el pueblo, decidieron buscar una mejora en la calidad de vida trabajando en Tarragona o Barcelona. Entre los autóctonos, esta emigración fue diferente de la que se puede observar en muchos municipios rurales catalanes por dos razones. No la puedo ubicar en un momento determinado, como pasa en otros lugares donde ocurrió en unos años determinados y de golpe. Además, en otros municipios se observa una voluntad constante entre las generaciones jóvenes de irse del pueblo y buscar más oportunidades en zonas urbanas. Nada de esto se observa en Vila-rodona. En este municipio la emigración es constante y parece responder en general a causas laborales, sobre todo entre personas con estudios superiores que no pueden ejercer en el pueblo. Esta poca voluntad de marcharse del pueblo es uno de los factores que he identificado para la gran cantidad de viviendas existentes en Vila-rodona; muchos de los que se fueron han mantenido su vivienda para pasar temporadas en ella o, si no tienen, se han comprado o construido viviendas nuevas. Muchas de estas viviendas se quedaron vacías al estallar la crisis, lo que favoreció la llegada de inmigrantes.

La llegada de inmigrantes extranjeros a Vila-rodona se empezó a producir en los años noventa. Los primeros en llegar fueron marroquíes y actualmente aún suponen el principal colectivo extranjero del municipio. En los años noventa el precio de la uva aumentó de manera muy importante, una escalada que se mantendría durante todos los años noventa para después bajar. Fue un momento de vacas gordas entre los agricultores, que empezaron a necesitar más mano de obra y se encontraron con que la población local ya no estaba dispuesta a realizar esos trabajos. En ese momento llegaron algunos marroquíes al pueblo buscando trabajo y los contrataron para la agricultura. Las cosas iban bien, hasta el punto de que algunos de ellos fueron contratados no solo por temporadas, sino todo el año. Aún se necesitaba más mano de obra y los trabajadores recomendaron a sus familias en Marruecos, muchos de los cuales fueron contratados en origen y traídos a Vila-rodona. Entonces también había mucha necesidad de mano de obra en la construcción, donde tampoco querían trabajar los vecinos autóctonos, de manera que muchos fueron contratados 
también en este sector. La llegada de población marroquí fue, pues, en cadena, los que venían traían a sus conocidos y familiares. Esto conlleva que prácticamente toda la población de origen marroquí proceda de la misma zona de ese país: Ksar El Kebir. En aquellos años también parece que algunos autóctonos ganaron dinero por traer de manera fraudulenta a familiares de los marroquíes. En todo caso, la población de origen marroquí se asentó en el municipio y al cabo de unos años empezaron a poder reagrupar a sus familias.

La reagrupación familiar se realizó a partir del año 2000, según mis informantes. En esos años el precio de la uva empezó a bajar, lo que coincidió con un aumento de la mecanización de los viñedos, y los agricultores dejaron de tener tanto interés en este tipo de cultivos, a la vez que necesitaban menos mano de obra para trabajarlos que anteriormente. Unos años después, al estallar la crisis, también los trabajadores de la construcción se quedaron sin empleo. En este contexto llegaron sus mujeres e hijos. Dentro de la lógica productivista con la que se interpretó la inmigración durante aquellos años en Europa, los inmigrantes ya no eran necesarios pues, o estaban en el paro, o quitaban el trabajo a los autóctonos. De manera que estas familias se vieron como una carga. Además, la llegada de las mujeres y los hijos de Marruecos aumentaron la visibilidad de los "moros" a nivel de espacio público, al empezar a tener una mayor presencia en el colegio, la plaza y la calle. Por otro lado, estas mujeres e hijos recién llegados en muchos casos llevaban diez años viviendo por sí mismas en Marruecos y no asumieron la emigración a Vila-rodona con mucho entusiasmo, según la técnica de inmigración. El nuevo contexto tampoco ayudó debido a la nueva cultura y porque, pese a ser rural, era muy diferente del contexto rural del que provenían, más aislado y duro. Todo ello se plasmó en unas relaciones tensas desde el principio entre autóctonos y mujeres e hijos marroquíes, tensión que se trasladó rápidamente a los hombres ya presentes años atrás.

Este proceso de reagrupación coincidió con la llegada de algunas personas de otros orígenes. Estas migraciones fueron más puntuales, aunque muchas también siguieron cadenas migratorias parecidas a las que desarrollaron los marroquíes. Llegó una familia muy extensa de origen portugués, de la que la primera en llegar fue una de las hermanas, casada con un catalán, que regentó un restaurante. Después de ella llegaron las otras cuatro hermanas con sus maridos e hijos. Portugal es la segunda nacionalidad con más habitantes en Vila-rodona. Le sigue Rumanía. Los rumanos han llegado también mediante 
cadenas migratorias, pero su peculiaridad es la manera en la que se han introducido en el mercado laboral: todos aquellos de los que he tenido noticias trabajan como masoveros en las masías de alrededor del pueblo. Parece ser que no hacen mucha vida en Vila-rodona y son bastante desconocidos en general. Los siguientes en número son los peruanos. Son una familia de dos hermanos con sus respectivas familias que llegaron también en cadena para trabajar en la pirotécnica del pueblo. El resto son familias o personas concretas que han llegado al pueblo por diferentes causas (búsqueda de un lugar mejor para vivir, noviazgos transnacionales...) y que vienen de Alemania, Inglaterra, Ucrania, Argelia, Brasil, Colombia... Aunque son pocos, crean una situación tan curiosa como que un pueblo como Vila-rodona tenga representación de catorce nacionalidades.

\section{Gráfico 2. Población extranjera según nacionalidad}



Fuente: Padrón de habitantes (Ayuntamiento de Vila-rodona) a fecha de 11/05/2011

\section{Ser autóctono en Vila-rodona}

Como he expuesto antes, Vila-rodona, como muchos otros municipios que a primera vista pueden parecer estáticos en cuanto a su población, cuenta en su historia reciente con unos importantes movimientos de población que han ido modelando lo que actualmente significa ser autóctono en este municipio.

En este pueblo, "ser" de allí es un estatus y solo se consigue cumpliendo dos condiciones: haber nacido allí y tener antepasados del mismo lugar. Por lo 
tanto, estamos ante una pertenencia "de sangre" (ius sanguinis), muy difícil de alcanzar por parte de los forasteros.

Esta lógica crea la paradoja de que personas hijas de inmigrantes castellanos, nacidas en Vila-rodona y que han vivido allí toda su vida, sean consideradas autóctonas, aunque hijas de forasteros. Y, a la vez, descendientes de familias de Vila-rodona de toda la vida son considerados autóctonos aunque no hayan vivido en el pueblo desde que son adultos.

[...] Però la majoria ja estan integrats i tot. Costa inclús recordar d’on vénen! [...], és la segona generació... [riu], és que és com per decantació, una mica la lògica natural, la primera generació és forastera i la filla, la filla de forasters i així..., si anem als dels anys cinquanta, els nens que neixen són més catalans que....! Clar... (Anna, Associació d'Amics del Gaià).

Respecto al hecho migratorio, pues, el inmigrante no solo nunca pierde del todo la condición de forastero, sino que tampoco sus hijos serán ajenos a ella. De la misma manera, quien es considerado autóctono nunca será considerado forastero, y sus descendientes tardarán en perder esa condición, todo ello muy en la línea del construccionismo social de Berger y Luckmann (1966).

La comunidad formada por los autóctonos está muy fuertemente ligada a la tierra y su tradición, lengua (catalana), cultura e historia. Y es que, al ser una comunidad pequeña y tener una pertenencia "de sangre", existe necesariamente una relación muy estrecha entre el legado y la historia familiar y el legado y la historia del municipio. Así, una cosa no se puede desligar de la otra, y los acontecimientos importantes del municipio serán vividos también en muchos casos como acontecimientos importantes de la propia familia.

Al mismo tiempo, los centros de poder y toma de decisiones (el Ayuntamiento y las principales entidades locales y asociaciones) están claramente en manos de los autóctonos. De esta manera, la identidad local no solo conlleva una fuerte vinculación con el municipio y su historia, sino también la capacidad de incidir en él. Es una relación dinámica: los autóctonos de Vila-rodona se sienten ligados al municipio y, a la vez, el municipio está ligado a ellos.

De esta manera, la identidad vila-rodonina (muy ligada a la identidad catalana) es una identidad "primordial" en el sentido de Geertz para sus autóctonos, pudiendo situarla más cerca de la identidad y el vínculo respecto a la propia 
familia que la identidad o vínculo respecto a una identidad nacional o de una gran ciudad. Sería una pertenencia a una comunidad real de Redfield ${ }^{1}$

La comunidad es fiel a su naturaleza (o a su modelo ideal) sólo en la medida en que sea "distintiva" respecto a otros grupos humanos (es evidente "dónde empieza y dónde acaba la comunidad"), "pequeña" (tan pequeña como para que todos sus miembros estén a la vista unos de otros) y "autosuficiente" (de tal modo que, según subraya Redfield, "provea todas las actividades y necesidades de las personas que incluya, o más de lo que necesitan. La pequeña comunidad cuida de sus miembros desde la cuna hasta la tumba") (Bauman, 2009: 6).

El hecho de que los autóctonos controlen las principales instancias de toma de decisiones del municipio les otorga también una posición de poder fáctico respecto a los otros grupos étnicos, que deben limitarse a acatar las decisiones sin poder influir en ellas.

La existencia de una identidad común entre los autóctonos no solo se manifiesta de manera interna, indicando quién pertenece a esta comunidad y tiene ciertos privilegios, sino que también se manifiesta externamente, señalando quién no pertenece a ella.

\section{Los no autóctonos en Vila-rodona: extranjeros e inmigrantes}

La población inmigrante es vista de una manera bastante compleja por parte de los autóctonos, y es que debemos tener en cuenta que hablamos de una comunidad local con una población muy pequeña y que, en última instancia, prácticamente podríamos encontrar una categoría para cada inmigrante, ya que casi todos son identificados personalmente por la mayoría de autóctonos. Aquí haré una descripción a más grandes rasgos.

Existen dos categorías principales entre los habitantes no autóctonos: los "inmigrantes" y los "extranjeros". La primera se refiere principalmente a los inmigrantes procedentes de Marruecos, Perú y Portugal, mientras que la segunda aglutina a las personas del resto de nacionalidades. Esta diferencia de términos

1. No he encontrado la descripción original de Redfield y he utilizado a Bauman, que hace referencia a esta. La cita original es Robert Redfield (1971), The Little Community and Peasant Society and cultura, Chicago, University of Chicago Press, pp. 4 y ss. 
plasma una diferencia de clase social atribuida a las diferentes nacionalidades, más allá de los individuos concretos. Así, se considera de una clase social superior a un inmigrante inglés que a uno marroquí, independientemente de su nivel económico.

"Inmigrantes" y "extranjeros" no provocan el mismo sentimiento en los autóctonos (pese a que todos ellos han llegado a Vila-rodona para vivir y trabajar). Además, los términos no se utilizan de manera objetiva o descriptiva, sino que tienen una importante carga calificativa. Los primeros causan recelo y rechazo, el mismo término inmigrante tiene un sentido despectivo en Vila-rodona. En cambio, los extranjeros causan cierta admiración e interés, teniendo la palabra extranjero un tono respetuoso. Los inmigrantes son vistos como personas que podrían quitarles algo que es suyo, mientras que los extranjeros se perciben como personas que aportan algo a la comunidad.

Esta distinción tan profundamente arraigada causa a veces desconcierto entre los mismos forasteros, que no entienden cómo se les puede negar el ser ambas cosas.

La gente se quejaba a nosotros sobre temas de los inmigrantes. Y siempre hemos pensado, qué raro, y a veces he dicho: "Yo soy inmigrante". Y ellos: “ $\mathrm{i}$, no, no! ¡Tú eres inglesa!” (Marta, inglesa).

\section{La población marroquí}

Dentro de estas categorías, cada comunidad nacional tiene atribuidas unas características, pero los marroquíes son especialmente estigmatizados y creo que son la comunidad que más se corresponde con el estereotipo "inmigrante" existente en Vila-rodona.

Probablemente esto se debe en gran parte a que constituyen la nacionalidad extranjera más numerosa, lo que los sitúa como una comunidad con un peso y un poder que no gusta nada a los autóctonos. De hecho, en algunas entrevistas se ha hecho referencia a la idea que arraigó en España en el momento de máxima llegada de inmigración de que los marroquíes quieren volver a conquistar el país.

I diuen quan arriba una patera aquí dalt, ja diuen: "Cap a Vila-rodona!" [...]. Que van així poc a poquet pujant per allà (Ramona, Associació de Dones). 
Aparece, pues, esta acusación de querer conquistar el lugar, de iniciar una invasión. Este pensamiento conlleva que los marroquíes encuentren, independientemente de sus actos, una mala disposición por parte de los autóctonos.

Una segunda razón por la que el colectivo marroquí es tan mal visto es su cultura, que es percibida como muy lejana y en muchos casos contraria o incompatible con la autóctona. Este pensamiento está bastante arraigado en España y es común a lo largo de la historia del territorio.

[...] [sobre la cultura àrab] és difícil diluir-se, com si diguéssim, amb una cultura tan diferent [...]. I llavors aquests costums sí que no són iguals amb els altres nouvinguts dels altres llocs. Que aquí sí que tenim un tema important, perquè és clar, hi ha una separació [...]. [La responsabilitat] jo crec que és de les dues parts, però en aquest cas més des de la cultura àrab, que marca més les distàncies (Anna, Associació d'Estudis del Gaià).

Los marroquíes son vistos como distantes y amenazadores, poco dignos de confianza, y todo ello debido a su cultura diferente e incompatible con la autóctona. De hecho, en el contexto español está arraigado desde hace muchos siglos un sentimiento de maurofobia importante, tal y como explica Martín Corrales (2004). Además, existe una lógica detrás que percibe la cultura árabe como más atrasada, menos moderna, que la occidental. De manera que los marroquíes son vistos como portadores de maneras de vivir que pueden crear conflictos con las existentes en el municipio y que son amenazadoras en parte quizás porque no se ven tan lejanas, como la diferenciación de género. Además, esta percepción es incompatible con la posibilidad de sentir comprensión y respeto hacia ellos, ya que son los marroquíes los que indudablemente tienen que evolucionar hacia un modo de vida occidental. De manera que, siguiendo esta lógica, los autóctonos parten de la premisa de que siempre tendrán la razón en cualquier conflicto cultural.

Y, dentro de la cultura árabe, la religión es vista como el foco de los problemas. Sobre todo, como desarrollaré más adelante, en torno al género: la diferente participación y presencia social de hombres y mujeres, las tareas diferenciadas, las vestimentas e incluso los malos tratos. Todo ello se encuadra siempre dentro de la lógica de la diferencia cultural o religiosa y nunca en la de la situación social y migratoria, aunque muchas veces sus razonamientos se 
refieran más a elementos de clase social o de modelo familiar que a diferencias culturales.

A lo largo del trabajo de campo he percibido que, en general, los inmigrantes marroquíes despertaban unos sentimientos diferentes del resto de inmigrantes (portugueses y peruanos). Sobre estos otros grupos nacionales los autóctonos hablan en un tono paternalista, inferiorizándolos y sin darles ninguna importancia. En cambio, cuando hablan de los marroquíes, transmiten cierto recelo, situándolos en un plano más amenazador.

Por todo ello, a partir de ahora me referiré a los inmigrantes de origen marroquí porque en torno a ellos los autóctonos han creado una estructura estigmatizadora y de exclusión.

\section{Inmigrantes: delincuentes o trabajadores, integra- dos o no integrados}

Los autóctonos, en su discurso, aluden muy frecuentemente de manera directa o indirecta a la legitimación que tienen los inmigrantes de estar en su municipio. Hay inmigrantes que parece que tengan más derecho que otros a estar en Vila-rodona. El requisito principal parece ser el hecho de estar trabajando o no, $y$, una vez que trabajan (cuando ya tienen "derecho" a estar), deben tener una conducta enfocada a su integración en la comunidad autóctona.

Y todo ello enmarcado en la misma lógica que describe Castien (2003: 77), según la cual los autóctonos se ven a sí mismos como los anfitriones del lugar:

El inmigrante viene a ser así concebido como una especie de huésped en casa ajena. Es alguien que "se nos viene", que no está en "su casa". Su presencia es resultado de un favor que se le hace, de una gracia que se le concede, y no de ningún derecho por él poseído. Este favor se otorga únicamente si tal presencia resulta beneficiosa, o al menos no perjudicial, para los propios autóctonos.

Los inmigrantes de origen marroquí fueron vistos a su llegada (años noventa) como una fuerza de trabajo que en ese momento era necesaria. Ello supuso que en esos primeros años su presencia fuera bien recibida y se considerara legítimo que estuvieran allí, ya que unos necesitaban trabajar y otros necesitaban trabajadores. 
En las entrevistas realizadas detecté que el hecho de que un inmigrante trabajara o no seguía siendo hoy en día un hecho muy importante a la hora de legitimar su presencia en el lugar, sin considerar la posibilidad de que el inmigrante no encuentre trabajo o, en el caso de que se considere, criticando su presencia por entender que, si no va a encontrar trabajo, no tiene sentido que siga aquí.

A veure, el que està clar és que hi ha tota una part d'immigració que ha vingut perquè han trobat feina i perquè séls hi ha donat feina. El problema és ara que no tenen aquesta feina. Una altra cosa és quan això deixa de passar. Quan no hi ha feina ni per ells ni pels d'aquí (Anna, Associació d’Amics del Gaià).

Esto conecta directamente con el discurso político de los años de bonanza económica, en los que se discutía sobre la necesidad o no de los inmigrantes y se establecían cupos según las necesidades de mano de obra. Igual que aquellos políticos, los informantes vila-rodonins ven a los inmigrantes como mano de obra que puede ser necesaria o no, y su presencia o su marcha, en su opinión, debería estar motivada por el simple hecho de tener o no tener trabajo, del servicio que puedan dar al municipio.

En esta concepción de los trabajadores como mano de obra interviene un factor socioeconómico que considero muy importante en todo el análisis de la percepción de la inmigración en Vila-rodona, sobre todo en torno a la inmigración procedente de Marruecos. Ese factor es que los inmigrantes son la mano de obra de los puestos de trabajo propiedad de los autóctonos. Por lo tanto, los inmigrantes que trabajan suelen hacerlo contratados por autóctonos, de modo que se establece una relación de poder que es muy cómoda para los autóctonos. Considerando el tamaño de la población, este elemento es aún más importante, ya que no solo estructura a propietarios contratadores autóctonos frente a trabajadores marroquíes, sino que la contratación de un trabajador por un autóctono es conocida por todos. Así, igual que a los autóctonos se los conoce por la familia a la que pertenecen (por ejemplo, Josep de Cal Fuster), a los inmigrantes se les conoce por su contratador, que al final también responde por ellos ante la comunidad.

El control social que se puede ejercer en un puesto de trabajo por parte de los propietarios y jefes se extiende, pues, al resto de la vida social del inmigrante-trabajador, quien, si tiene un mal comportamiento en el pueblo fuera de las horas de trabajo, puede ver su puesto peligrar, mientras que, si es bien valorado 
en su puesto de trabajo, recibirá un mayor respeto y reconocimiento en el resto de relaciones sociales que mantenga con los autóctonos.

Para una población en la que escasea el trabajo, todo este sistema de control es muy efectivo y otorga un gran poder a la comunidad autóctona. Ello se puede ver claramente cuando algún marroquí pretende crear su propio negocio. Según algunos informantes, se pusieron muchas trabas para la apertura del único negocio regentado por un marroquí, una tienda de comestibles, y se ha imposibilitado la apertura de un locutorio, que finalmente se abrió en otro municipio.

Y es que el surgimiento de una población marroquí comerciante significaría su emancipación respecto de los autóctonos y su control social, además de un cambio en el paisaje local que no sería bien recibido. De hecho, está muy mal visto por los autóctonos que uno de sus miembros compre en ese negocio.

En cuanto a los inmigrantes que no trabajan, más allá de la poca legitimidad que se les dé para seguir en el municipio, se llega a sospechar de sus fuentes de ingresos, más o menos fundamentadamente. Su nivel socioeconómico bajo, unido a la diferente cultura y en la mayoría de casos su juventud, hace a los marroquíes sin trabajo muy distantes de la mayor parte de autóctonos y, por lo tanto, más susceptibles de negocios como el tráfico de drogas, que los autóctonos creen que puede ser una forma de vida deseable para unas personas a las que ven tan diferentes.

Sí, tenen 30 i pico, els jovens tomben, fan els seus negocis, entre cometes... Trapichean? Suposo que sí. Suposo que sí. Molta desocupació tenen, també? O no volen treballar. (xiuxiuejant). Bueno, desocupació per les raons que sigui. Aquests jovens és desocupació de no volguer treballar. No d'ara perquè no n'hi ha, però fa tres o quatre anys quan hi havia per treballar tampoc treballaven, eh? (Jaume, president del Casal).

Perquè per ells la maria, la marihuana, és una cosa, per ells, legal, però aquí no ho és, eh? I dius: “Aquest de què treballa? I com és que viu tan bé?". I et dones compte que sempre està a determinada hora aquí o allà i passa droga. Però també en tenim del país, de camells (Jordi, alcalde).

Otra manera de explicarse que los inmigrantes puedan vivir sin trabajar en Vila-rodona es que viven de las ayudas, lo que no goza de mejor reputación que 
vivir del trapicheo. Para los autóctonos, que un inmigrante viva de las ayudas es como si viviera de regalo, aprovechándose del país en el que está.

Jo no sé ni com mengen. Com poden menjar. Perquè els hi donen. Van a Càrites, van a demanar. Ah. Aqui hi ha Càrites? No, cap a Valls..., els hi donen ajudes. Perquè aquells d'allí baix encara van una mica més brutets, però els altres..., aquestos que tenen tres nenes van impecables sempre. I de dalt bax enconjuntades, eh? (Ramona, Associació de Dones).

En esta cita se ve claramente que la informante considera negativamente que personas que van bien vestidas y no parecen pasar necesidad estén llevando este tren de vida gracias a las ayudas. Este razonamiento conecta directamente con el anterior, según el cual quien no trabaje no tiene razón para seguir viviendo en Vila-rodona. De la misma manera, quien no trabaje y esté mantenido por el Estado o las ONG, se está aprovechando de la situación.

Más allá de trabajar o no, y siguiendo la lógica de que los inmigrantes son huéspedes en casa ajena, se les exige una voluntad de integración. Los anfitriones lo son de un lugar fuertemente vinculado a un idioma, el catalán, y a unas tradiciones y costumbres, todo ello propio de un territorio. Por lo tanto, los inmigrantes deben integrarse en el territorio en el que viven, que queda desligado de la comunidad de autóctonos. Estos solo pueden facilitarles el proceso compartiendo todo aquello que es propio del municipio.

El esfuerzo de integración es unilateral, y deben ser los inmigrantes los que quieran hacerlo. No se considera positivo el hecho de que la vida social y cultural del pueblo cambie debido a la presencia de inmigrantes. Estos deben esconder o dejar a un lado sus diferencias culturales y "aprender" la manera de vivir del lugar.

El proceso de integración se puede encuadrar desde la perspectiva del proceso ritual descrito por Turner. Pienso que este proceso se puede aplicar si los inmigrantes tienen como meta llegar a ser autóctonos y convertirse en miembros con pleno poder de la comunidad local. Las fases de este proceso son: separación (en la que los inmigrantes se alejan de sus costumbres y formas de vida culturales), liminalidad (en la que no son ni inmigrantes ni autóctonos) y agregación (en la que el inmigrante ya no lo es).

En mi opinión, los inmigrantes nunca pueden llegar a finalizar este proceso por el hecho de que quienes forman parte de la comunidad autóctona lo son 
por derecho de sangre, como antes he expuesto. De esta manera, a lo máximo que pueden llegar los inmigrantes es a ser inmigrantes integrados, quedándose en un estado de liminalidad. Por lo tanto, la integración que exigen los autóctonos es falaz, ya que es un proceso imposible de culminar.

Y es que ningún inmigrante, ni siquiera los castellanos que llegaron de niños en los años sesenta, se escolarizaron en el pueblo y han vivido siempre en el municipio, es considerado como los autóctonos. Así, a aquellos se les sigue considerando castellanos y, por ello, siguen siendo forasteros.

Además, los inmigrantes a los que se considera "integrados" pueden perder fácilmente su estatus, como podemos ver en la cita siguiente, en la que una informante autóctona habla de un marroquí al que se le consideró durante un tiempo ejemplo de integración:

Però aquell paleta, aquell xicot del Tomás, va marxar per quatre dies i es va estar tres o quatre mesos. I quan va venir es va pensar que encara tenia la feina. I el Tomás va haver de llogar un altre. Pues ara tomba pel poble, sí. Oh, no pot ser quatre mesos! Si ho féssim, a tots ens passaria el mateix, no? Si marxes tres o quatre mesos, quan tornis, res de res. Pues ells no entenen això, ells marxen tres o quatre mesos al seu pueblo i quan torni ja ho arreglarem. Aquell que era apreciat pel poble, aquell xicot que tothom d'allò, que hasta les canalles..., però fa això..., i mira (Ramona, Associació de Dones).

Esta persona, pese a pasar unos años haciendo todo aquello que se esperaba de ella como inmigrante con voluntad de integrarse, nunca llegó a ser considerado como uno más de la comunidad autóctona, y cuando ocurrió algo negativo en el plano estrictamente laboral, se le dio por perdido.

Un inmigrante integrado sigue en una fase liminal ya que su posición final no es estable, sigue a disposición del grupo y se le puede devolver muy fácilmente a su estatus inicial. Todo ello nos indica que no ha llegado a finalizar su proceso.

\section{La alteridad dentro de los otros}

El género es un importante factor diferenciador en los discursos de los autóctonos acerca de los marroquíes. Las mujeres son las que se llevan la peor parte en cuanto a críticas, ya que son consideradas aún más incompatibles o distantes que los hombres. 
Empezando por el modo de ver a los inmigrantes como fuerza de trabajo, las mujeres marroquíes, que no suelen acceder al mercado laboral, son percibidas como poco legitimadas para estar en el municipio.

Hay un gran componente también de naturalización de la cultura y la religión atribuida a los marroquíes (tanto hombres como mujeres). Al provenir de esa cultura, son machistas y menosprecian a las mujeres por su género. Esto, pese a provocar rechazo entre los autóctonos, se supone como normal para esa comunidad y no se contempla que puedan ser de otra manera. Como he comentado antes, no se tienen en cuenta los factores sociales en un trato machista, sino que se considera un rasgo cultural más que además es compartido por hombres y mujeres, asumiendo así que las propias mujeres comparten esta manera de pensar.

Al definir la situación de las musulmanas se da implícitamente por supuesto que el islam es su enemigo, degrada su dignidad y las somete a un nivel infrahumano (Moualhi, 2000: 298).

Además, me llamó mucho la atención la gran división por género existente en las propias críticas de la población autóctona hacia los marroquíes. A los hombres se los critica por comportamientos proactivos: por no ser cumplidores como trabajadores, por machistas, por tener malos modales, etc. Mientras que a las mujeres, en cambio, se las critica por aspectos mucho más personales e involuntarios: por su manera de vestir, por su higiene personal, por llevar velo, lo que no gusta, o por no dejarse ver, porque entonces es que están encerradas en casa debido a su cultura. Esta gran diferenciación en las críticas es muy importante, ya que los hombres simplemente deberían cambiar sus actitudes para ser aceptados. En cambio, las mujeres deberían abandonar comportamientos o maneras de vivir mucho más profundos para dejar de ser criticadas.

El que passa és que és això que van amb la canalla i la van a buscar, i ara a la tarda per jugar aquí a la plaça tampoc no estan. Surten els homes. Surten els homes amb la canalla. Abans deien que les obligaven a estar a casa. Deien. Deien. El que passa és que no ho sé. Molta cosa ja deu ser d'ells mateixos. De la seva cultura (Ramona, Collectiu de Dones).

Esta divergencia en la consideración de las mujeres y los hombres marroquíes pienso que también tiene ciertas raíces en la propia cultura, que considera a las mujeres como las garantes de la tradición, respecto a la cual actúan como 
reproductoras y transmisoras. A ellas se les atribuye también el ámbito familiar y más íntimo, mientras que se considera que los hombres se mueven en un ámbito social.

Estas construcciones de género no son muy lejanas de las existentes tradicionalmente en la cultura de los autóctonos. Por lo tanto, se da la paradoja de estigmatizar a los marroquíes por unos valores y estereotipos que también son propios de la sociedad autóctona.

\section{Situaciones de exclusión en Vila-rodona}

La problematización de la inmigración en Vila-rodona no solo aparece ante los usos diferenciados del espacio público por parte de los inmigrantes, sino también (y sobre todo) ante su presencia, que es rechazada cuando se da en un plano de igualdad: cuando los inmigrantes cruzan la frontera de su papel como trabajadores (inferiores) y pasan a ejercer de ciudadanos. Entonces los autóctonos reaccionan creando espacios restringidos para los otros que no están trazados por fronteras visibles, sino por mecanismos mucho más sutiles. Estos mecanismos implican en casi todos los casos una acción colectiva por parte de los autóctonos como no ir a comprar a la tienda halal o presionar para no dejar entrar a los marroquíes en el bar.

Los ámbitos de exclusión que detecté son los siguientes: vivienda, patrones de consumo, emprendeduría, lugares de ocio o bares y participación, y trabajo. A continuación desarrollo dos ejemplos: un caso concreto de exclusión mediante la acción colectiva en el bar del Casal que me pareció muy interesante y el caso del acceso a la vivienda en Vila-rodona.

El bar del Casal es simbólicamente el bar más importante de Vila-rodona. Es tanto lugar de encuentro como escenario de diferentes actividades y actos sociales a lo largo del año. Quizás por todo ello, cuando un grupo de hombres marroquíes empezó a frecuentarlo cada tarde, los autóctonos reaccionaron muy mal. Según cuentan mis informantes autóctonos, los problemas surgieron a raíz de que hubo peleas entre ellos en las que aparecieron cuchillos, de que miraban a las mujeres de manera ofensiva y de que se pasaban toda la tarde sin consumir. En cualquier caso, su presencia en ese bar provocó que los autóctonos, especialmente las mujeres, dejaran de frecuentarlo y empezaran a quejarse a la junta del Casal. En poco tiempo, desde esta entidad se decidió que quien no 
fuera socio no podía estar en el bar, de manera que los clientes marroquíes, que no lo eran, dejaron de tener derecho a frecuentarlo, y los clientes autóctonos volvieron.

En cuanto al acceso a la vivienda, según he podido observar, la mayoría de propietarios no quieren alquilar a personas de origen marroquí, ya que existe la creencia de que no van a pagar el alquiler. Además, se percibe un cierto miedo ante la idea de tener que ir a exigir dinero a alguien de esa comunidad. Por lo que he podido saber, solo una persona está dispuesta a alquilar viviendas a este sector de la población, y compra inmuebles antiguos y en mal estado y se los ofrece por el precio que considera justo. Para los inmigrantes marroquíes, la única manera de alquilar una vivienda en Vila-rodona es a través de esta persona, independientemente de su poder adquisitivo.

En todos los ámbitos analizados, la segregación implica la aparición de al menos dos escenarios diferentes y paralelos: uno para los autóctonos y otro para los marroquíes. A algunos de ellos se accede mediante canales también diferentes, como se puede ver en el ejemplo de la vivienda. Tanto los canales como los escenarios son privilegiados en el caso de los autóctonos y marginales en el caso de los marroquíes.

Otro elemento en común es la estructuración de los usos del espacio por parte de los autóctonos. Estos manifiestan rechazo a que los marroquíes estén presentes en determinados lugares y/o de determinadas maneras. Este hecho choca con el discurso que se repite entre los autóctonos de que los inmigrantes deben integrarse y que esta integración pasa necesariamente por aprender el catalán y participar en el pueblo. Claramente, la participación a la que se refieren no es una participación que ponga de manifiesto el multiculturalismo existente, sino que es una participación mediante la aculturación según las reglas y pautas de los autóctonos.

Detrás de esta demanda existe un argumento muy a tener en cuenta: el mantenimiento de las tradiciones del pueblo. El estudio sobre valores urbanos y rurales en Cataluña de E. Trepat y M. Serret (2011) afirma que los catalanes consideran que en el entorno rural se da más valor a las tradiciones que en el urbano y que los elementos que estructuran la identidad en este entorno están más relacionados con el territorio y sus costumbres. En este sentido, parece que la participación diferenciada de los nuevos vecinos pueda suponer un trasiego mayor que en un contexto urbano. Pienso que este es un argumento que, 
aunque existe, se da a posteriori del rechazo, es un intento de mostrarlo de una manera heroica como un acto necesario para mantener la tradición popular que los municipios rurales tienen el deber de conservar. La prueba es que este argumento no aparece cuando se trata de que los inmigrantes de otras nacionalidades participen. $\mathrm{Y}$, en el fondo, muestra un miedo al cambio que pienso que tiene mucho que ver con el miedo a perder el control. Ante un número de personas "diferentes" que tienen otras costumbres, el equilibrio de poderes a favor de los autóctonos puede peligrar y sería impensable una renegociación de las posiciones de cada grupo.

Esta renegociación pasaría indudablemente por el espacio público, en el que la urbanidad primera, entendida a la manera de Carlos Giménez (2005) una vez que llegan los inmigrantes, se debe renegociar para alcanzar un nuevo equilibrio hecho de normas y códigos comprensibles por todos. Al evitar seguir el proceso, lo que se está provocando es que el conflicto siga latente y que simplemente se gestione la convivencia con este, a lo que el mismo autor llama acomodación.

Esta acomodación, por parte de los autóctonos, pasa por la necesidad de mantener los propios espacios y tradiciones y, por lo tanto, de vetar ciertos espacios a quien los pone en peligro. Rodríguez (2008) explica la existencia de una estructura de sentimientos entre los leridanos frente a la llegada de inmigrantes. Estos relacionan a los inmigrantes con "la incomodidad, al miedo a perder alguna cosa — desde el bolso a la identidad-y por lo tanto a la inseguridad" (Rodríguez, 2008).

En Vila-rodona los autóctonos también sienten incomodidad (ante la diferencia que suponen los inmigrantes y los cambios que conllevan en las pautas de relación), que se traduce en miedo a perder alguna cosa (o a cambiar), pero la reacción última no sería la inseguridad. Los vila-rodonins ven peligrar su manera de vivir y su entorno pretendidamente homogéneo y reaccionan defendiendo sus espacios. No están dispuestos a afrontar la situación, así que utilizan todo su poder para evitarla; si los marroquíes no actúan como es "normal", son vetados del lugar.

En el texto de Gabriela Rodríguez (2008), el miedo de los leridanos es a perder "desde el bolso a la identidad", pero en el caso de los vila-rodonins este miedo se centra mucho más en la pérdida de la identidad. Una identidad común que está muy ligada al territorio más inmediato (el pueblo) y sus costumbres. 
En este sentido, la existencia de un gran número de asociaciones y la realización de numerosas actividades pueden estar relacionadas con esta reafirmación (y recreación) de la propia identidad local que acompaña al miedo a perderla.

El hecho de que los autóctonos hayan desarrollado acciones colectivas es un elemento más de esta reafirmación del propio grupo, ya que identifican un enemigo colectivo a la vez que un objetivo conjunto, y todo ello fomenta la unión del grupo de los autóctonos. Todo ello, en última instancia, favorece una mayor cohesión interna de este grupo étnico.

\section{Conclusiones}

A modo de comentario final, quiero resaltar algunos elementos importantes que se pueden encontrar mucho más desarrollados en la investigación de la que parte este texto. En primer lugar, la existencia de una identidad autóctona local muy profundamente arraigada entre la población local de este municipio que es indesligable de otros elementos de identidad primarios como la familia.

Los puestos de poder y de toma de decisiones están en manos de los habitantes autóctonos, que se caracterizan por tener una pertenencia de sangre a su comunidad, difícilmente alcanzable para cualquier persona no nacida en el municipio y sin antecedentes familiares en él.

En segundo lugar, también quiero destacar la existencia de diferentes "tipos" de inmigrantes. Dependiendo del lugar de donde vengan (y de la imagen que se tenga de ese lugar), así como de su situación socioeconómica o su voluntad de integración, serán percibidos de maneras extremamente diferentes. En este sentido, como he explicado anteriormente, existen dos categorías muy diferenciadas: inmigrantes y extranjeros. Los primeros son considerados como fuerza de trabajo y se deben integrar, y los segundos, como vecinos exóticos.

Dentro del primer grupo, los marroquíes acaparan mi atención en el resto del artículo por constituir la mayor parte del grupo y por tener un mayor nivel de estigmatización y rechazo. Cuando los autóctonos describen este grupo, llama la atención una gran diferenciación de género. Ellas son consideradas por varias razones lo más alejado culturalmente $y$, en muchos casos, como incompatibles con la forma de vida local.

Asimismo, cabe resaltar que los conflictos que han podido existir se han dado en el plano social, ya que en el contexto laboral las relaciones de los au- 
tóctonos con los marroquíes han sido fluidas. En este plano social he detectado diferentes situaciones de exclusión hacia los marroquíes, poniendo como ejemplos el conflicto en el bar y el diferente acceso a la vivienda. Como podemos ver, especialmente en el segundo ejemplo, provocan que los habitantes de origen marroquí tengan que utilizar canales de acceso diferenciados de los del resto de vecinos y que estos les lleven a una oferta, en este caso inmobiliaria, de más baja calidad que la que pueden encontrar los habitantes autóctonos.

En definitiva, considero que esta investigación pone de relieve los procesos sociales que se están dando también en los municipios rurales en torno a la llegada de inmigrantes, procesos mucho menos estudiados que los que se desarrollan en las ciudades. Estos procesos sociales no solo inciden en la manera como los habitantes perciben la llegada de nueva población, sino que también intervienen de manera muy intensa en la evolución de la identidad local y en su intensificación.

\section{Bibliografía}

Bauman, Z. (2006). Comunidad: en busca de seguridad en un mundo hostil. Madrid: Siglo XXI.

Berger, P. y Luckmann, T. (1966). La construcción social de la realidad. Buenos Aires: Amorrotu.

Checa, J. C; Arjona Garrido, A. y Checa Olmos, F. (2010). “El Ejido elegido: la convivencia como desafío", Scripta Nova, 315.

Elias, N. (1976). "Ensayo acerca de las relaciones entre establecidos y forasteros", Reis, 104/03, pp. 219-251.

Geertz, C. (1988). La interpretación de las culturas. Barcelona: Gedisa.

Giménez Romero, C. (2005).“Convivencia: Conceptualización y sugerencias para la praxis", Puntos de vista. Cuadernos del Observatorio de las Migraciones $y$ de la Convivencia Intercultural de la Ciudad de Madrid, núm. 1.

Martín Corrales, E. (2004). "Maurofobia/islamofobia y maurofilia/islamofilia en la España del siglo xxI", Revista CIDOB d'Afers Internacionals, 66-67: "Representaciones e interculturalidad", 39-51.

Moualhi, D. (2000). "Mujeres musulmanas: estereotipos occidentales versus realidad social", Papers, 60, 291-304. 
Riera, C. (2007). "Integració, convivència i espai públic". En VV. AA.: Els diferents rostres de la immigració (pp. 35-40). Olot: Edicions Municipals (Ajuntament d'Olot).

Rodríguez Fernández, G. (2008)."El miedo al otro y el uso del espacio: el discurso sobre el delito y el conflicto en la ciudad de Lérida", Scripta Nova, 270 (16), vol. XII.

Trepat, E. y Serret, M. (2011). "Valors relacionats amb els individus i les seves relacions socials". En E. Trepat y M. Serret: Valors rurals i valors urbans a Catalunya. Lleida: Fundació del Món Rural.

Turner, V. (1988). El proceso ritual. Estructura y antiestructura. Madrid: Taurus.

VArgas, A. y CAsas, J. (2006). "El capital social rural”, KAIROS, revista de temas sociales, núm. 18. 